OPEN ACCESS

Edited by:

Yasuyuki Saito,

Kobe University, Japan

Reviewed by:

Susumu Goyama,

The University of Tokyo, Japan

Todd Pitts,

University of Colorado, United States

${ }^{*}$ Correspondence: Yong-Guang Yang yongg@jlu.edu.cn

Wentao Liu

liuwtt70@163.com

Specialty section:

This article was submitted to

Cancer Immunity and

Immunotherapy,

a section of the journal

Frontiers in Immunology

Received: 05 August 2020 Accepted: 22 September 2020

Published: 08 October 2020

Citation:

Sun L, Jin C-H, Tan S, Liu W and Yang $Y-G$ (2020) Human

Immune System Mice With

Autologous Tumor for Modeling

Cancer Immunotherapies.

Front. Immunol. 11:591669.

doi: 10.3389/fimmu.2020.591669

\section{Human Immune System Mice With Autologous Tumor for Modeling Cancer Immunotherapies}

\author{
Liguang Sun ${ }^{1,2}$, Chun-Hui Jin ${ }^{1,3}$, Shulian Tan ${ }^{1,2}$, Wentao Liu ${ }^{1,2 *}$ \\ and Yong-Guang Yang ${ }^{1,2,4 *}$
}

${ }^{1}$ Key Laboratory of Organ Regeneration \& Transplantation of the Ministry of Education, The First Hospital of Jilin University, Changchun, China, ${ }^{2}$ National-local Joint Engineering Laboratory of Animal Models for Human Diseases, Jilin University, Changchun, China, ${ }^{3}$ Department of Pathology, The First Hospital of Jilin University, Changchun, China, ${ }^{4}$ International Center of Future Science, Jilin University, Changchun, China

Mouse models are the most commonly used in vivo system for biomedical research, in which immune-related diseases and therapies can be investigated in syngeneic and immunologically intact hosts. However, because there are significant differences between rodent and human, most findings from conventional mouse models cannot be applied to humans. The humanized mouse with a functional human immune system, also referred to as human immune system (HIS) mouse, is the only model available to date for in vivo studies in real-time of human immune function under physiological and pathological conditions. HIS mice with human tumor xenografts are considered an emerging and promising in vivo model for modeling human cancer immunotherapy. In this review, we briefly discuss the protocols to construct HIS mice and elaborate their pros and cons. Particular attention is given to HIS mouse models with human tumor that is autologous or genetically identical to the human immune system, which are discussed with examples of their usefulness in modeling human cancer immunotherapies.

Keywords: humanized mouse, cancer, immunotherapy, CAR T cell, human immune system mouse, allogeneic hematopoietic cell transplantation

\section{INTRODUCTION}

Human immune system (HIS) mice have been highly instrumental for in vivo studies of human immune function and immune disorders. The HIS mouse was the first model that made it possible to study human immune responses in real time in vivo under physiologic or pathogenic conditions, such as HIV pathogenesis (1), human xeno-immune responses (2), complex interplay between hypercholesterolemia and human adaptive immunity (3), and intrathymic selections of human T cells (4). HIS mice, conjunct with tissue chimeras (i.e., with organ repopulation by human parenchymal cells), were found highly valuable in elucidating immunopathology of humantropic viral infections, such as hepatitis $B$ and hepatitis $C$ viruses $(5,6)$ and respiratory viruses (7). HIS mice were also increasingly used in the studies of human cancer immunology and immunotherapy. However, most of the models used in these studies were either 
immunocompromised or involving allogeneic and/or xenogeneic immune responses, making the host immune environment different from that of patients. Thus, there is an urgent and unmet need for a preclinical mouse model mimicking the patients, in which both the immunity and the tumor are of human origin and genetically identical. In this review, we first briefly overview the development and evolution of HIS mouse protocols, then discuss progress to date in creating HIS mice with autologous or genetically identical human tumors.

\section{BRIEF REVIEW OF HIS MOUSE CONSTRUCTION}

There has been a long-standing effort to create and optimize HIS mouse models. While different HIS mouse construction protocols have been reported, all involve transplantation of human hematopoietic and/or lymphoid cells (e.g., peripheral blood lymphocytes (PBLs), bone marrow cells, cord blood cells, or fetal liver hematopoietic cells) into immunodeficient mice. Current HIS mouse models are in general derived from three HIS mouse models reported in the late 1980s. Mosier and colleagues reported in 1988 that injection of human PBLs into C.B-17 severe combined immunodeficiency (SCID) mice resulted in durable reconstitution with human T cells, B cells and monocytes/macrophages, providing a useful model for the study of human immune function (known as hu-PBL-SCID mouse) (8). During the same period, McCune and colleagues reported another HIS mouse model (referred to as SCIDhu mouse by the authors), in which human immune reconstitution was achieved in C.B-17 SCID mice by transplantation of fetal thymus, liver and lymph node (9). Subsequently, using bg/nu/xid mice Kamel-Reid and Dick found that transplantation of human hematopoietic stem/progenitor cells (HSCs/HPCs) into immunodeficient mice could achieve human HSC/HPC engraftment and differentiation, offering an additional HIS mouse model (referred to as chimeric human/immune-deficient (HID) mice by the authors) (10). However, this HID model or similarly created HIS mouse models (i.e., constructed by human HSCs/HPCs of different sources) were not very useful for the study of human immunity due to poor $\mathrm{T}$ cell function until better immunodeficient mouse strains became available (see discussion below), and was further improved by using newborn immunodeficient mice as the recipients $(11,12)$. Despite these improvements, human $\mathrm{T}$ cells developing in the xenogeneic mouse thymus were increasingly reported to be functionally abnormal, likely caused by poor HLArestricted antigen recognition (13-15).

The hu-PBL-SCID model is simple, but it needs to be cautious when using this model because of the potential of infused human $\mathrm{T}$ cells to induce xenogeneic graft-versus-host disease (GVHD) that may confound assessment of human immunity and result in human effector T cell anergy (16). Although there are apparent differences between xenogeneic and allogeneic GVHD, the huPBL-SCID model was found useful in the study of human GVHD pathogenesis (17). Xenogeneic GVHD was effectively prevented in the human fetal thymus/liver (Thy/Liv)-grafted
SCID-hu model, in which the majority of human $\mathrm{T}$ cells developed de novo in the murine host and therefore, those reactive to mouse antigens were purged during the negative selection process (9). However, we found that, due to the lack of sufficient repopulation with human dendritic cells (DCs) and B cells, the SCID-hu mice were inefficient in mounting antigenspecific immune responses in vivo (18). To solve this problem, we developed a new protocol in which HIS mice were made by combined transplantation of human fetal thymus (under renal capsule) and CD $34^{+}$HSCs/HPCs (i.v.) $(18,19)$. The resultant HIS mice showed reconstitution with human T cells, B cells and DCs, and acquired the ability to mediate robust antigen-specific immune responses in vivo and reject pig xenografts (19-22). These human Thy/HSC-grafted HIS mice were also found able to mediate anti-viral responses and were termed BLT mice in some other studies $(23,24)$. A disadvantage of the Thy/HSC-based HIS mouse model is the need to use fetal tissues. Therefore, increasing efforts are currently undertaken to optimize the potential of animal thymi to support human thymopoiesis. However, until such animal becomes available, the Thy/HSC HIS mouse model will likely still be instrumental.

Regardless of which protocol is used to construct HIS mice, magnificent improvements in engraftment and function of human hematopoietic and lymphoid cells were made by using more sophisticated immunodeficient mouse strains, such as nonobese diabetic/LtSz-scid/scid (NOD/SCID) (25) and NOD-scid IL2R $\gamma^{\text {null }}$ (NSG) (26) mice. C.B-17 SCID mice, which were most commonly used in HIS mouse construction before the availability of NOD/ SCID mice, have high complement activity that mediates antibodyindependent rejection of xenogeneic cells (27). CD47 is ligand of SIRP $\alpha$, an inhibitory receptor on macrophages and DCs, and its engagement with SIRP $\alpha$ inhibits phagocytosis and endocytosis (28, 29). In a xenogeneic transplant setting, the inability of donor CD47 to interact with the recipient SIRP $\alpha$ is an important mechanism triggering donor cell rejection by macrophages $(30,31)$. NOD/SCID mice lack hemolytic complement, and express signal regulatory protein (SIRP) $\alpha$ capable of cross-reacting with human CD47 (32). In addition, substantial effort was made to improve the engraftment, differentiation, survival, and function of human hematopoietic and lymphoid cells in immunodeficient mice by introducing human cytokines. The MISTRG mouse is a good example, in which human M-CSF, GM-CSF/IL-3, and TPO genes are knocked into their respective mouse loci (33). HIS mice made with MISTRG mice showed markedly improved development and function of human innate immune cells than those made with NSG mice (33). However, it is worth mention that HIS mice carrying transgenes of human immunostimulatory cytokines under a constitutive promoter, e.g., the SGM3-NSG mice expressing human SCF, GM-CSF, and IL-3, are prone to develop fatal disease characterized by activation and widespread tissue infiltration of human $\mathrm{T}$ cells and macrophages, and show significant elevation in human proinflammatory cytokines including IL-6, IL-18, IFN- $\gamma$, and TNF- $\alpha(34,35)$. The vigorous proinflammatory responses would likely confound the evaluation of interested immune functions in these HIS mice, such as cytokine storm or cytokine release syndrome induced by immunotherapies (36). 


\section{CONSTRUCTION OF HIS MICE WITH AUTOLOGOUS TUMOR}

There has been an emerging effort in developing human tumorbearing HIS mouse models. Both human tumor cell derived xenograft (CDX; immunodeficient mice grafted with human cancer cell line cells) and patient-derived xenograft (PDX; immunodeficient mice grafted with patient cancer cells) models were widely and successfully used in understanding oncogenesis and testing anti-cancer drugs (37), these models, however, were not useful in the study of cancer immunology or immunotherapy due to the lack of human immune system. A conceivable approach to solve this problem is to construct human tumor-bearing HIS mouse models, in which both the tumor cells and the immune system are of human origin, which permit assessment of tumorassociated immune responses and immunotherapies. However, a notable limitation of such human tumor-bearing HIS mouse models is that the tumor cells are allogeneic to human immune system, so anti-tumor immune responses are expected to be largely driven by allogenicity rather than tumorigenicity. Although cotransplantation of tumor cells with immune cells (e.g., PBMCs) from the same patient may resolve this issue, this model will also suffer the same problem as the hu-PBL-SCID model discussed above (i.e., xenogeneic GVHD and human effector T cell anergy).

\section{HIS Mice With Autologous Human Leukemia}

An ideal approach to resolving allogenicity would be to construct HIS mice with autologous tumor. Recently, we developed a HIS mouse model with spontaneous autologous leukemia and validated its usefulness in exploring anti-human leukemia immunotherapies. In this model, we transplanted sublethally-irradiated NSG mice with human fetal thymus and fetal liver $\mathrm{CD} 34^{+}$cells that were virally transduced with a mixed-lineage leukemia (MLL) fusion gene MLLAF9 (Figure 1A) (38). It has been shown that MLL-AF9 expression drives the development of acute leukemia that resembles several clinical hallmarks of MLL leukemias (39). The NSG mice grafted with Thy/MLL-AF9-HSC appeared normal and showed a gradual increase in the levels of human PBMCs, including T cells, B cells and myeloid cells for about 3 to 4 months, then became progressively ill with a sharp increase in MLL-AF9-expressing HSC-derived CD19 ${ }^{+}$ cells in blood. Autopsy revealed splenomegaly, enlarged lymph nodes, and hepatomegaly in all moribund mice. Histology demonstrated massive leukemic cell infiltration in bone marrow, spleen, lung, liver, and kidney. The MLL-AF9-expressing HSCderived leukemic cells exhibited a high nucleus/cytoplasm ratio with a B-ALL phenotype, i.e., $\mathrm{CD} 19^{+} \mathrm{CD} 10^{+} \mathrm{CD} 20^{-} \mathrm{sIgM}^{\text {low/ }} \mathrm{sIgD}^{\text {low/- }}$ $\mathrm{CD} 44^{\mathrm{hi}} \mathrm{MHC}-\mathrm{I}^{+} \mathrm{MHC}-\mathrm{II}^{\mathrm{hi}}$ and negative for other lineage markers, i.e., $\mathrm{CD} 33^{-} \mathrm{CD} 15^{\text {low } /-} \mathrm{CD} 14^{-} \mathrm{CD} 11 \mathrm{~b}^{-} \mathrm{CD} 3^{-} \mathrm{CD} 4^{-} \mathrm{CD} 8^{-} \mathrm{CD} 56^{-}$. The study demonstrated that the Thy/MLL-AF9-HSC HIS mice not only develop human lymphohematopoietic cells, but also autologous B-ALL, offering a model to study human leukemia immunopathology and anti-leukemia immunotherapy in an autologous setting.

B-ALL cells developed in MLL-AF9-HSC-grafted HIS mice are transplantable in immunodeficient mice and in HIS mice with an established autologous human immune system (i.e., HIS mice made with human Thy/HSC from the same fetus from which $\mathrm{CD} 34^{+}$cells were used to develop the B-ALL) (38). However, rejection was seen when the B-ALL cells were transplanted in HIS mice with an allogeneic immune system. Adoptive transfer of cryopreserved BALL cells in pre-established HIS mice with an autologous immune system would present a much simpler model than spontaneous leukemia model described above (Figure 1B).

\section{HIS Mice With Autologous Human Solid Tumor}

This model may also possibly be applied to set up HIS mice bearing autologous solid tumor. Although there has been no report of successful construction of autologous human solid tumor-bearing
A

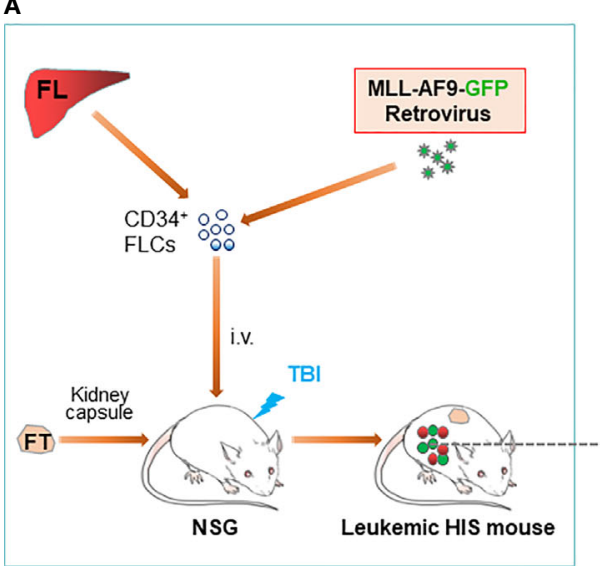

B

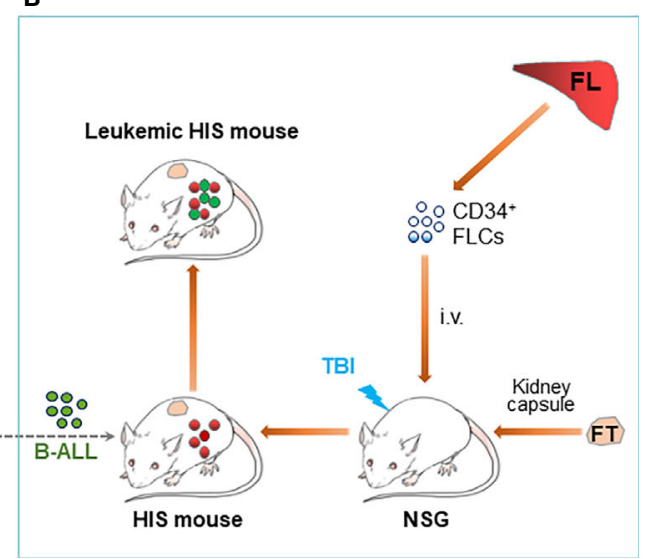

FIGURE 1 | Construction of leukemic HIS mice with human immune system and leukemia derived from genetically identical HSCs/HPCs. (A) Schematic showing preparation of HIS mice with spontaneous development of B-ALL autologous to the human immune system. (B). Schematic of leukemic HIS mouse construction by injection of autologous B-ALL [made as described in (A)] into preestablished HIS mice. FL, fetal liver; FLC, fetal liver cell; FT, fetal thymus; TBI, total body irradiation. 
HIS mice, the feasibility of developing such HIS mouse models is supported by progress in understanding oncogenic changes causing tumorigenic transformation of normal cells. Previous studies were successful in inducing melanocytic transformation by engineering normal melanocytes to express a combination of specific mutations found in human melanoma, and the engineered human melanocytes could develop into melanocytic tumor in immunodeficient mice (40). Other studies identified combinations of oncogenic mutants that may drive tumorigenic transformation of human lung epithelial cells $(41,42)$. These studies suggested the possibility of establishing tumorigenic cells from normal fetal tissue cells. Successful generation of tumorigenic cells from fetal tissue cells would make it possible to construct HIS mice bearing autologous solid tumors by injecting the tumor cells into autologous HIS mice (i.e., HIS mice made with human Thy/HSC from the fetus from which parenchymal tissue cells are engineered for tumorigenesis). The feasibility of this approach is supported by a previous study, in which HIS mice were successfully used to assess the immunogenicity of autologous human induced pluripotent stem (iPS) cells (i.e., iPS cells reprogramed from fetal liver fibroblasts of the same fetus used for constructing HIS mice) (43).

\section{Personalized HIS Mice With Patient- Specific Immunity and Tumor}

HIS mouse models were also used to study human immune function in a personalized manner, in which immunodeficient mice were grafted with patient-derived $\mathrm{CD} 34^{+}$bone marrow cells along with partially HLA allele-matched fetal thymic tissue (44). In this model, although human T cells were more "naïve" than those of the adult $\mathrm{CD} 34^{+}$cell donors, the immune recognition mimicked that of the adult donor, offering a model for individualized analysis of human immune function $(44,45)$. Furthermore, while the fetal thymus used was partially HLAmatched to the patient, human $\mathrm{T}$ cells developing in personalized HIS mice showed specific "self" tolerance (i.e., tolerance to the
CD $34^{+}$cell donor patient). Combining this personalized HIS mouse with PDX model would provide a means of constructing patient-specific tumor-bearing HIS mice, in which both the tumor (leukemia or solid tumor) and immune system are derived from the same patient (Figure 2). Such a patientspecific tumor-bearing HIS mouse model should be highly valuable in personalized therapies.

\section{MODELING ANTI-LEUKEMIA IMMUNOTHERAPY IN HIS MICE WITH AUTOLOGOUS B-ALL}

\section{Anti-Leukemic Responses Induced by Recipient Leukocyte Infusion}

Following allogeneic hematopoietic cell transplantation (alloHCT), donor T cells mediate beneficial graft-vs.-tumor (GVT) effects. However, allogeneic donor $\mathrm{T}$ cells also attack recipient normal tissues, resulting in GVHD. It has been reported that, in patients receiving nonmyeloablative allo-HCT, some of the patients who rejected donor grafts unexpectedly showed sustained remissions, suggesting an anti-donor alloresponseassociated antitumor activity (46). In support of this possibility, studies in mice found that administration of recipient leukocyte infusion (RLI) to mixed allogeneic chimeras results in rejection of donor hematopoietic chimerism and significant anti-host leukemia responses (47). RLI is apparently less effective than alloreactive donor $\mathrm{T}$ cells in killing recipient leukemia (48), but it does not induce GVHD, offering a potentially safe treatment for use in combination with other immunostimulatory therapies.

We have tested the potential of lymphopenia to enhance antitumor effects of RLI in leukemic HIS mice (Figure 1) (38). Lymphopenia is common in patients with leukemia who receive allo-HCT $(49,50)$, which is a factor that triggers $\operatorname{GVHD}(51,52)$

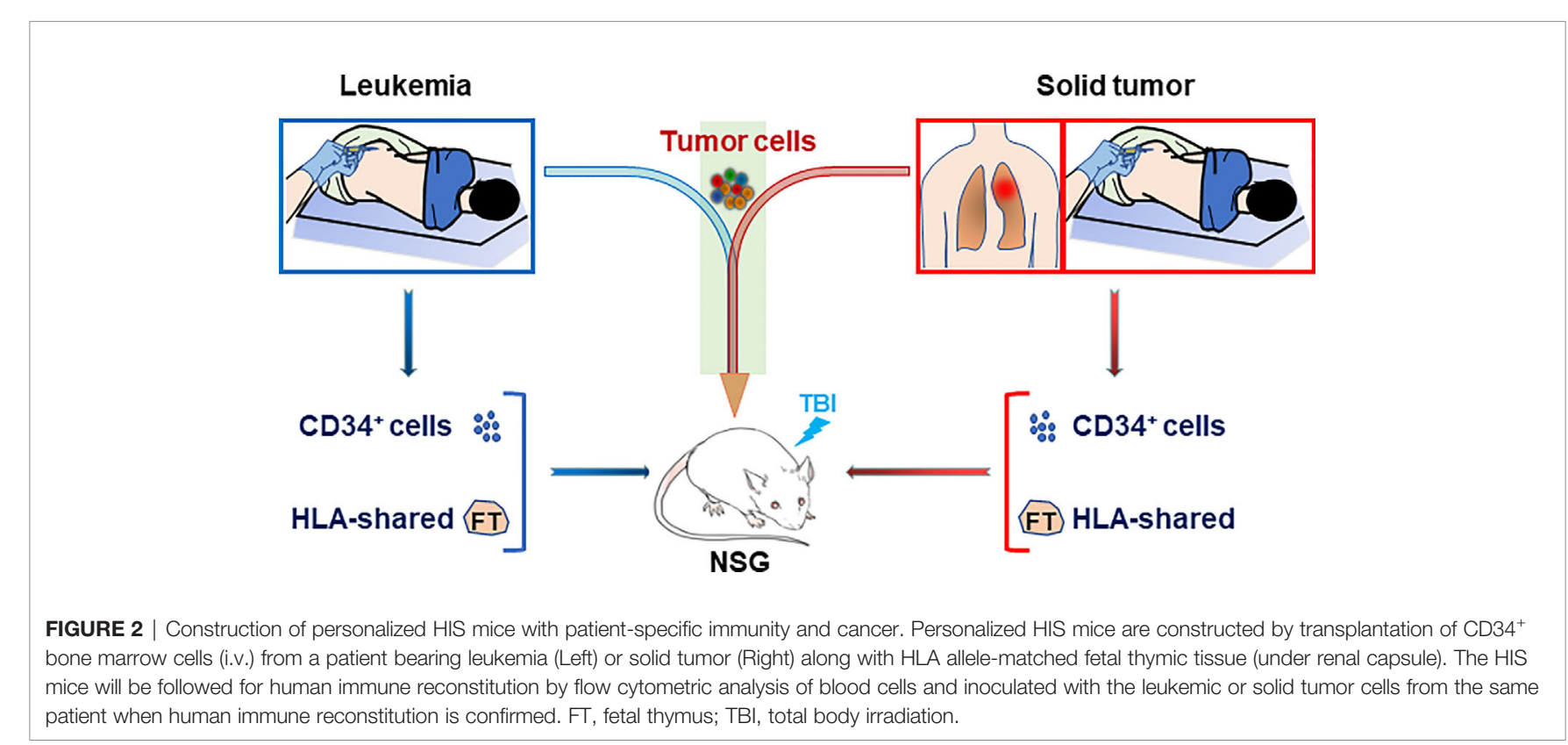


but also promotes antitumor responses $(53,54)$. In this study, mixed chimeric (MC) HIS mice were established by transplantation of human Thy along with a mixture of 'recipient' (genetically identical to the Thy graft) and allogeneic 'donor' CD $34^{+}$HSCs, and lymphopenia was made by treatment with anti-huCD3-immunotoxin. Spleen cells from HIS mice made by transplantation of 'recipient' Thy/CD $34^{+}$cells were used as the RLI cells, which were autologous to the 'recipient' and allogeneic to the 'donor' origin of the MC HIS mice. Using this model, it was found that, in a human immune system, RLI was significantly more effective in inducing antitumor responses in lymphopenic than non-lymphopenic recipients, and that the antitumor response was associated with rejection of donor hematopoietic chimerism (38). The findings suggested that RLI offers a potentially safer clinical treatment option for leukemic patients who have profound lymphopenia.

\section{CD19-Targeted CAR T Cell Therapy}

Recently, we made use of these leukemic HIS mice to model adoptive immunotherapy using human $\mathrm{T}$ cells that were genetically engineered to express anti-CD19 chimeric antigen receptors (CARs). CD19-targeted CAR T cell therapy has achieved promising results in patients with B-cell malignancies (55-57). However, despite the impressive response rates, many patients showed relapse or severe adverse reaction after anti-CD19 CAR T cell therapy $(58,59)$. Although memory CAR T cells were detected in patients (60), our understanding of these memory $\mathrm{T}$ cells, including their differentiation, function, self-renewal, and survival factors/signaling, remains limited. In addition, it remains largely unknown about the mechanisms responsible for the toxicities associated with anti-CD19 CAR T cell therapy, such as cytokine-release syndrome (CRS), which can be severe or even fatal (61). Thus, there is an urgent need to develop a preclinical model, which can be used to understand relapse and toxicity associated with human CAR T cell therapy, and to test the efficacy of new CAR $\mathrm{T}$ cells. Immunodeficient mice grafted with human B-ALL (PDX models) were found useful in testing CD19-targeted human CAR T cell therapy (62), but these models are either lacking host immunity or involving allo- and/or xeno-immune responses. Because the

\section{REFERENCES}

1. McCune J, Kaneshima H, Krowka J, Namikawa R, Outzen H, Peault B, et al. The SCID-hu mouse: a small animal model for HIV infection and pathogenesis. Annu Rev Immunol (1991) 9:399-429. doi: 10.1146/annurev.iy.09.040191. 002151

2. Hu Z, Yang YG. Human lymphohematopoietic reconstitution and immune function in immunodeficient mice receiving cotransplantation of human thymic tissue and CD34(+) cells. Cell Mol Immunol (2012) 9:232-6. doi: $10.1038 / \mathrm{cmi} .2011 .63$

3. Proto JD, Doran AC, Subramanian M, Wang H, Zhang M, Sozen E, et al. Hypercholesterolemia induces $\mathrm{T}$ cell expansion in humanized immune mice. J Clin Invest (2018) 128:2370-5. doi: 10.1172/JCI97785

4. Li Y, Teteloshvili N, Tan S, Rao S, Han A, Yang YG, et al. Humanized Mice Reveal New Insights Into the Thymic Selection of Human Autoreactive CD8 (+) T Cells. Front Immunol (2019) 10:63. doi: 10.3389/fimmu.2019.00063 leukemic HIS mouse model described above has a functional human immune system and genetically-matched (autologous) primary B-ALL, this model was used to model CD19-targeted CAR T cell therapy (63). Another unique feature of this model is that the anti-CD19 CAR-expressing human $\mathrm{T}$ cells are also genetically-identical (autologous) to the human components (both normal and malignant human cells) and tolerant to mouse antigens of the HIS mice, and therefore do not mediate alloresponses against human or xenoresponses against mouse antigens. In leukemic HIS mice receiving CAR T cell therapy, the kinetics and levels of antiCD19 CAR T cells in the peripheral blood were similar to those in patients (60). In agreement with clinical studies $(55,56)$, the frequency of CAR T cells in blood showed an inverse correlation with B-ALL burden but a positive correlation with survival times in CAR T cell-treated leukemic HIS mice. Moreover, this model was also found useful in characterizing cytokine profiles and regulatory $\mathrm{T}$ (Treg) cell generation and function following CAR T cell therapy. These observations provide a proof-of-principle that this leukemic HIS mouse model has the potential to be used to evaluate human CAR $\mathrm{T}$ cell therapy and help design new CARs with enhanced antitumor activity.

\section{CONCLUDING REMARKS}

Apparently, the HIS mouse is not identical to a human host. However, there is strong experimental evidence for the value and feasibility of using HIS mice to study human immunity, including antigen-specific $\mathrm{T}$ cell and antibody responses (1823, 64, 65). Thus, HIS mice with autologous tumors, either leukemia or solid tumor, would provide a highly valuable preclinical model for in vivo studies of human cancer immunology and immunotherapy.

\section{AUTHOR CONTRIBUTIONS}

All authors contributed to the article and approved the submitted version.
5. Barth H, Robinet E, Liang TJ, Baumert TF. Mouse models for the study of HCV infection and virus-host interactions. J Hepatol (2008) 49:134-42. doi: 10.1016/j.jhep.2008.03.012

6. Cheng L, Li F, Bility MT, Murphy CM, Su L. Modeling hepatitis B virus infection, immunopathology and therapy in mice. Antiviral Res (2015) 121:18. doi: 10.1016/j.antiviral.2015.06.012

7. Wahl A, De C, Abad Fernandez M, Lenarcic EM, Xu Y, Cockrell AS, et al. Precision mouse models with expanded tropism for human pathogens. Nat Biotechnol (2019) 37:1163-73. doi: 10.1038/s41587-019-0225-9

8. Mosier DE, Gulizia RJ, Baird SM, Wilson DB. Transfer of a functional human immune system to mice with severe combined immunodeficiency. Nature (1988) 335:256-9. doi: 10.1038/335256a0

9. McCune J, Namikawa R, Kaneshima H, Shultz L, Lieberman M, Weissman I. The SCID-hu mouse: murine model for the analysis of human hematolymphoid differentiation and function. Science (1988) 241:1632-9. doi: $10.1126 /$ science.2971269 
10. Kamel-Reid S, Dick J. Engraftment of immune-deficient mice with human hematopoietic stem cells. Science (1988) 242:1706-9. doi: 10.1126/science.2904703

11. Traggiai E, Chicha L, Mazzucchelli L, Bronz L, Piffaretti JC, Lanzavecchia A, et al. Development of a human adaptive immune system in cord blood celltransplanted mice. Science (2004) 304:104-7. doi: 10.1126/science.1093933

12. Ishikawa F, Yasukawa M, Lyons B, Yoshida S, Miyamoto T, Yoshimoto G, et al. Development of functional human blood and immune systems in NOD/ SCID/IL2 receptor \{gamma\} chain(null) mice. Blood (2005) 106:1565-73. doi: 10.1182/blood-2005-02-0516

13. Shultz LD, Saito Y, Najima Y, Tanaka S, Ochi T, Tomizawa M, et al. Generation of functional human T-cell subsets with HLA-restricted immune responses in HLA class I expressing NOD/SCID/IL2r gamma(null) humanized mice. Proc Natl Acad Sci U S A (2010) 107:13022-7. doi: 10.1073/ pnas. 1000475107

14. Strowig T, Gurer C, Ploss A, Liu YF, Arrey F, Sashihara J, et al. Priming of protective $\mathrm{T}$ cell responses against virus-induced tumors in mice with human immune system components. J Exp Med (2009) 206:1423-34. doi: 10.1084/ jem. 20081720

15. Watanabe Y, Takahashi T, Okajima A, Shiokawa M, Ishii N, Katano I, et al. The analysis of the functions of human B and T cells in humanized NOD/shiscid/gammac(null) (NOG) mice (hu-HSC NOG mice). Int Immunol (2009) 21:843-58. doi: 10.1093/intimm/dxp050

16. Tary-Lehmann M, Lehmann PV, Schols D, Roncarolo MG, Saxon A. AntiSCID mouse reactivity shapes the human CD4+ T cell repertoire in hu-PBLSCID chimeras. J Exp Med (1994) 180:1817-27. doi: 10.1084/jem.180.5.1817

17. Purtilo DT, Falk K, Pirruccello SJ, Nakamine H, Kleveland K, Davis JR, et al. SCID mouse model of Epstein-Barr virus-induced lymphomagenesis of immunodeficient humans. Int J Cancer (1991) 47:510-7. doi: 10.1002/ ijc. 2910470407

18. Lan P, Wang L, Diouf B, Eguchi H, Su H, Bronson R, et al. Induction of human $\mathrm{T}$-cell tolerance to porcine xenoantigens through mixed hematopoietic chimerism. Blood (2004) 103:3964-9. doi: 10.1182/blood2003-10-3697

19. Lan P, Tonomura N, Shimizu A, Wang S, Yang YG. Reconstitution of a functional human immune system in immunodeficient mice through combined human fetal thymus/liver and CD34+ cell transplantation. Blood (2006) 108:487-92. doi: 10.1182/blood-2005-11-4388

20. Tonomura N, Habiro K, Shimizu A, Sykes M, Yang YG. Antigen-specific human $\mathrm{T}$-cell responses and $\mathrm{T}$ cell-dependent production of human antibodies in a humanized mouse model. Blood (2008) 111:4293-6. doi: 10.1182/blood-2007-11-121319

21. Tonomura N, Shimizu A, Wang S, Yamada K, Tchipashvili V, Weir GC, et al. Pig islet xenograft rejection in a mouse model with an established human immune system. Xenotransplantation (2008) 15:129-35. doi: 10.1111/j.13993089.2008.00450.x

22. Habiro K, Sykes M, Yang YG. Induction of human T-cell tolerance to pig xenoantigens via thymus transplantation in mice with an established human immune system. Am J Transplant (2009) 9:1324-9. doi: 10.1111/j.16006143.2009.02646.x

23. Melkus MW, Estes JD, Padgett-Thomas A, Gatlin J, Denton PW, Othieno FA, et al. Humanized mice mount specific adaptive and innate immune responses to EBV and TSST-1. Nat Med (2006) 12:1316-22. doi: 10.1038/nm1431

24. Brainard DM, Seung E, Frahm N, Cariappa A, Bailey CC, Hart WK, et al. Induction of robust cellular and humoral virus-specific adaptive immune responses in human immunodeficiency virus-infected humanized BLT mice. J Virol (2009) 83:7305-21. doi: 10.1128/JVI.02207-08

25. Shultz LD, Schweitzer PA, Christianson SW, Gott B, Schweitzer IB, Tennent B, et al. Multiple defects in innate and adaptive immunologic function in NOD/ LtSz-scid mice. J Immunol (1995) 154:180-91.

26. Shultz LD, Lyons BL, Burzenski LM, Gott B, Chen X, Chaleff S, et al. Human lymphoid and myeloid cell development in NOD/LtSz-scid IL2R gamma null mice engrafted with mobilized human hemopoietic stem cells. J Immunol (2005) 174:6477-89. doi: 10.4049/jimmunol.174.10.6477

27. Yang YG, Chen AM, Sergio JJ, Zhou Y, Sykes M. Role of antibodyindependent complement activation in rejection of porcine bone marrow cells in mice. Transplantation (2000) 69:163-5. doi: 10.1097/00007890200001150-00027
28. Oldenborg PA, Zheleznyak A, Fang YF, Lagenaur CF, Gresham HD, Lindberg FP. Role of CD47 as a marker of self on red blood cells. Science (2000) 288:2051-4. doi: 10.1038/ni1527

29. Wang H, Madariaga ML, Wang S, Van Rooijen N, Oldenborg PA, Yang YG. Lack of CD47 on nonhematopoietic cells induces split macrophage tolerance to CD47null cells. Proc Natl Acad Sci U S A (2007) 104:13744-9. doi: 10.1126/ science.288.5473.2051

30. Wang $\mathrm{H}$, VerHalen J, Madariaga ML, Xiang S, Wang S, Lan P, et al. Attenuation of phagocytosis of xenogeneic cells by manipulating CD47. Blood (2007) 109:836-42. doi: 10.1073/pnas.0702881104

31. Ide K, Wang H, Tahara H, Liu J, Wang X, Asahara T, et al. Role for CD47SIRP $\alpha$ signaling in xenograft rejection by macrophages. Proc Natl Acad Sci (2007) 104:5062-6. doi: 10.1182/blood-2006-04-019794

32. Takenaka K, Prasolava TK, Wang JC, Mortin-Toth SM, Khalouei S, Gan OI, et al. Polymorphism in Sirpa modulates engraftment of human hematopoietic stem cells. Nat Immunol (2007) 8:1313-23. doi: 10.1073/pnas.0609661104

33. Rongvaux A, Willinger T, Martinek J, Strowig T, Gearty SV, Teichmann LL, et al. Development and function of human innate immune cells in a humanized mouse model. Nat Biotechnol (2014) 32:364-72. doi: 10.1038/ nbt. 2858

34. Yoshihara S, Li Y, Xia J, Danzl N, Sykes M, Yang YG. Posttransplant Hemophagocytic Lymphohistiocytosis Driven by Myeloid Cytokines and Vicious Cycles of T-Cell and Macrophage Activation in Humanized Mice. Front Immunol (2019) 10:186. doi: 10.3389/fimmu.2019.00186

35. Wunderlich M, Stockman C, Devarajan M, Ravishankar N, Sexton C, Kumar AR, et al. A xenograft model of macrophage activation syndrome amenable to anti-CD33 and anti-IL-6R treatment. JCI Insight (2016) 1:e88181. doi: 10.1172/jci.insight.88181

36. Norelli M, Camisa B, Barbiera G, Falcone L, Purevdorj A, Genua M, et al. Monocyte-derived IL-1 and IL-6 are differentially required for cytokinerelease syndrome and neurotoxicity due to CAR T cells. Nat Med (2018) 24:739-48. doi: 10.1038/s41591-018-0036-4

37. Hidalgo M, Amant F, Biankin AV, Budinska E, Byrne AT, Caldas C, et al. Patient-derived xenograft models: an emerging platform for translational cancer research. Cancer Discov (2014) 4:998-1013. doi: 10.1158/21598290.CD-14-0001

38. Xia J, Hu Z, Yoshihara S, Li Y, Jin CH, Tan S, et al. Modeling Human Leukemia Immunotherapy in Humanized Mice. EBioMedicine (2016) 10:1018. doi: 10.1016/j.ebiom.2016.06.028

39. Barabe F, Kennedy JA, Hope KJ, Dick JE. Modeling the initiation and progression of human acute leukemia in mice. Science (2007) 316:600-4. doi: 10.1126/science.1139851

40. Chudnovsky Y, Adams AE, Robbins PB, Lin Q, Khavari PA. Use of human tissue to assess the oncogenic activity of melanoma-associated mutations. Nat Genet (2005) 37:745-9. doi: 10.1038/ng1586

41. Sato M, Larsen JE, Lee W, Sun H, Shames DS, Dalvi MP, et al. Human lung epithelial cells progressed to malignancy through specific oncogenic manipulations. Mol Cancer Res (2013) 11:638-50. doi: 10.1158/15417786.MCR-12-0634-T

42. Sato M, Shay JW, Minna JD. Immortalized normal human lung epithelial cell models for studying lung cancer biology. Respir Invest (2020) 58:344-54. doi: 10.1016/j.resinv.2020.04.005

43. Zhao T, Zhang ZN, Westenskow PD, Todorova D, Hu Z, Lin T, et al. Humanized Mice Reveal Differential Immunogenicity of Cells Derived from Autologous Induced Pluripotent Stem Cells. Cell Stem Cell (2015) 17:353-9. doi: 10.1016/j.stem.2015.07.021

44. Kalscheuer H, Danzl N, Onoe T, Faust T, Winchester R, Goland R, et al. A model for personalized in vivo analysis of human immune responsiveness. Sci Transl Med (2012) 4:125ra30. doi: 10.1126/scitranslmed.3003481

45. Borsotti C, Danzl NM, Nauman G, Holzl MA, French C, Chavez E, et al. HSC extrinsic sex-related and intrinsic autoimmune disease-related human B-cell variation is recapitulated in humanized mice. Blood Adv (2017) 1:2007-18. doi: 10.1182/bloodadvances.2017006932

46. Dey BR, McAfee S, Colby C, Cieply K, Caron M, Saidman S, et al. Antitumour response despite loss of donor chimaerism in patients treated with non-myeloablative conditioning and allogeneic stem cell transplantation. $\mathrm{BrJ}$ Haematol (2005) 128:351-9. doi: 10.1111/j.1365-2141.2004.05328.x 
47. Rubio MT, Kim YM, Sachs T, Mapara M, Zhao G, Sykes M. Antitumor effect of donor marrow graft rejection induced by recipient leukocyte infusions in mixed chimeras prepared with nonmyeloablative conditioning: critical role for recipient-derived IFN-gamma. Blood (2003) 102:2300-7. doi: 10.1182/blood2002-12-3949

48. Saito TI, Rubio MT, Sykes M. Clinical relevance of recipient leukocyte infusion as antitumor therapy following nonmyeloablative allogeneic hematopoietic cell transplantation. Exp Hematol (2006) 34:1270-6. doi: 10.1016/j.exphem.2006.04.022

49. Heining C, Spyridonidis A, Bernhardt E, Schulte-Monting J, Behringer D, Grullich $\mathrm{C}$, et al. Lymphocyte reconstitution following allogeneic hematopoietic stem cell transplantation: a retrospective study including 148 patients. Bone Marrow Transplant (2007) 39:613-22. doi: 10.1038/sj.bmt.1705648

50. Small TN, Papadopoulos EB, Boulad F, Black P, Castro-Malaspina H, Childs $\mathrm{BH}$, et al. Comparison of immune reconstitution after unrelated and related T-cell-depleted bone marrow transplantation: effect of patient age and donor leukocyte infusions. Blood (1999) 93:467-80. doi: 10.1182/blood.V93.2. 467.402k22_467_480

51. Li HW, Sachs J, Pichardo C, Bronson R, Zhao G, Sykes M. Nonalloreactive T cells prevent donor lymphocyte infusion-induced graft-versus-host disease by controlling microbial stimuli. J Immunol (2012) 189:5572-81. doi: 10.4049/ jimmunol.120004

52. Miller JS, Weisdorf DJ, Burns LJ, Slungaard A, Wagner JE, Verneris MR, et al. Lymphodepletion followed by donor lymphocyte infusion (DLI) causes significantly more acute graft-versus-host disease than DLI alone. Blood (2007) 110:2761-3. doi: 10.1182/blood-2007-05-090340

53. Dudley ME, Wunderlich JR, Robbins PF, Yang JC, Hwu P, Schwartzentruber DJ, et al. Cancer regression and autoimmunity in patients after clonal repopulation with antitumor lymphocytes. Science (2002) 298:850-4. doi: $10.1126 /$ science. 1076514

54. Quezada SA, Simpson TR, Peggs KS, Merghoub T, Vider J, Fan X, et al. Tumor-reactive CD4+ T cells develop cytotoxic activity and eradicate large established melanoma after transfer into lymphopenic hosts. J Exp Med (2010) 207:637-50. doi: 10.1084/jem.20091918

55. Brentjens RJ, Davila ML, Riviere I, Park J, Wang X, Cowell LG, et al. CD19targeted $\mathrm{T}$ cells rapidly induce molecular remissions in adults with chemotherapy-refractory acute lymphoblastic leukemia. Sci Transl Med (2013) 5:177ra38. doi: 10.1126/scitranslmed.3005930

56. Grupp SA, Kalos M, Barrett D, Aplenc R, Porter DL, Rheingold SR, et al. Chimeric antigen receptor-modified $\mathrm{T}$ cells for acute lymphoid leukemia. N Engl J Med (2013) 368:1509-18. doi: 10.1056/NEJMoa1215134
57. Park JH, Riviere I, Gonen M, Wang X, Senechal B, Curran KJ, et al. LongTerm Follow-up of CD19 CAR Therapy in Acute Lymphoblastic Leukemia. N Engl J Med (2018) 378:449-59. doi: 10.1056/NEJMoa1709919

58. Sotillo E, Barrett DM, Black KL, Bagashev A, Oldridge D, Wu G, et al. Convergence of Acquired Mutations and Alternative Splicing of CD19 Enables Resistance to CART-19 Immunotherapy. Cancer Discov (2015) 5:1282-95. doi: 10.1158/2159-8290.CD-15-1020

59. Jackson HJ, Brentjens RJ. Overcoming Antigen Escape with CAR T-cell Therapy. Cancer Discov (2015) 5:1238-40. doi: 10.1158/2159-8290.CD-151275

60. Kalos M, Levine BL, Porter DL, Katz S, Grupp SA, Bagg A, et al. T cells with chimeric antigen receptors have potent antitumor effects and can establish memory in patients with advanced leukemia. Sci Transl Med (2011) 3:95ra73. doi: 10.1126/scitranslmed.3002842

61. Neelapu SS, Tummala S, Kebriaei P, Wierda W, Gutierrez C, Locke FL, et al. Chimeric antigen receptor T-cell therapy - assessment and management of toxicities. Nat Rev Clin Oncol (2018) 15:47-62. doi: 10.1038/nrclinonc. 2017.148

62. Qin H, Cho M, Haso W, Zhang L, Tasian SK, Oo HZ, et al. Eradication of BALL using chimeric antigen receptor-expressing $\mathrm{T}$ cells targeting the TSLPR oncoprotein. Blood (2015) 126:629-39. doi: 10.1182/blood-2014-11-612903

63. Jin $\mathrm{CH}$, Xia J, Rafiq S, Huang X, Hu Z, Zhou X, et al. Modeling anti-CD19 CAR $T$ cell therapy in humanized mice with human immunity and autologous leukemia. EBioMedicine (2019) 39:173-81. doi: 10.1016/j.ebiom.2018.12.013

64. Tan S, Li Y, Xia J, Jin CH, Hu Z, Duinkerken G, et al. Type 1 diabetes induction in humanized mice. Proc Natl Acad Sci U S A (2017) 114:10954-9. doi: $10.1073 /$ pnas.1710415114

65. Rong Z, Wang M, Hu Z, Stradner M, Zhu S, Kong H, et al. An effective approach to prevent immune rejection of human ESC-derived allografts. Cell Stem Cell (2014) 14:121-30. doi: 10.1016/j.stem.2013.11.014

Conflict of Interest: The authors declare that the research was conducted in the absence of any commercial or financial relationships that could be construed as a potential conflict of interest.

Copyright (C) 2020 Sun, Jin, Tan, Liu and Yang. This is an open-access article distributed under the terms of the Creative Commons Attribution License (CC BY). The use, distribution or reproduction in other forums is permitted, provided the original author(s) and the copyright owner(s) are credited and that the original publication in this journal is cited, in accordance with accepted academic practice. No use, distribution or reproduction is permitted which does not comply with these terms. 